\title{
Museus e famílias: percepções e comportamentos de crianças e seus familiares em exposições para o público infantil
}

\author{
Museums and families: \\ the perceptions and \\ behavior of children and \\ their families at \\ children's exhibits
}

STUDART, D. C.: Museus e famílias: percepções e comportamentos de crianças e seus familiares em exposições para o público infantil.

História, Ciências, Saúde-Manguinhos, v. 12 (suplemento), p. 55-77, 2005.

Este artigo apresenta resultados de pesquisa de doutorado realizada em três exposições interativas, planejadas para o público infantil e famílias. Duas delas ocorreram em museus londrinos: All Hands Gallery, no National Maritime Museum e Launch Pad, no Science Museum. "Me \& My Body", foi montada no Eureka! The Museum for Children, na cidade de Halifax. A metodologia adotada e os achados obtidos são uma contribuição para o estudo de público de família em museus e serve como referência e base de comparação para estudos na área desenvolvidos em outros países. No Brasil, são ainda poucas as pesquisas realizadas em museus que tenham buscado 'conhecer' o público composto por grupos familiares que visitam essas instituições. A investigação demonstrou que tais ambientes são um importante produto cultural e educativo do museu para o público infantil e de famílias.

PALAVRAS-CHAVE: exposições interativas, pesquisa de público, estudos de visitantes, aprendizagem em museus, educação não formal, público infantil e famílias.

STUDART, D. C.: Museums and families: the perceptions and behavior of children and their families at children's exhibits.

História, Ciências, Saúde - Manguinhos, v. 12 (supplement), p. 55-77, 2005.

The article presents findings from doctoral research conducted at three interactive exhibits for children and family audiences. Two took place at museums in London (the National Maritime Museum's All Hands Gallery and the Science Museum's Launch Pad) while the third "Me E My Body"- was on display at Eureka! The Museum for Children, in Halifax. Both the methodology adopted and the research findings are a contribution to the study of the family audience at museums and are meant to serve as a reference and a basis for comparison in similar studies conducted in other countries. Few museum studies in Brazil have sought to 'get to know' the audience comprising family groups that visit these institutes. My research showed that for children and their families these environments are an important cultural and educational product.

Denise C. Studart

Museóloga do Museu da Vida Casa de Oswaldo Cruz/Fiocruz Av. Brasil 4365, Manguinhos, 21040-900 Rio de Janeiro - RJ Brasil dstudart@coc.fiocruz.br
KEYWORDS: interactive exhibits, audience research, visitor studies, learning at museums, informal education, children and family audiences. 


\section{Introdução}

$\mathrm{O}$ crescimento dos estudos de público em museus, durante as últimas décadas, forneceu novos entendimentos sobre a experiência museal do visitante, assim como informações importantes sobre suas expectativas, preferências e seus interesses. Esses estudos vêm ajudando os profissionais de museus a conceber e planejar exposições e atividades que melhor atendam às necessidades e interesses de diferentes públicos.

Falk e Dierking (1992) afirmam que a experiência museal é o resultado da interação de três contextos: o contexto físico (espaço, arquitetura, objetos), o contexto pessoal (interesses individuais, experiências prévias, formação, educação) e o contexto social (com quem o indivíduo visita e/ou interage no museu - escola, família, amigos, monitores, guias etc.). $\mathrm{O}$ reconhecimento dessas dimensões que afetam a experiência do visitante oferece ao profissional de museu um quadro bastante útil para o planejamento de espaços e atividades.

Em relatório comissionado a Anderson (1997, p. 37) pela Museums \& Galleries Comission - A common Walth:museums and learning in the United Kingdom (Um bem comum: museus e aprendizagem no Reino Unido) -, o autor reconhece os museus como centros de aprendizagem e sugere que, no plano estratégico dessas instituições, 'pesquisa e avaliação tornem-se parte integrante da prática museal'. O relatório identifica exemplos de uma possível agenda para pesquisas sobre aprendizagem em museus. Incluem-se entre os tópicos: como os museus podem ajudar pais e professores a estimular o aprendizado das crianças, durante e após a visita; as necessidades específicas de diferentes públicos-alvos; como os visitantes utilizam as exposições e os aparatos interativos; os benefícios da educação não-formal; e a natureza da aprendizagem nesses espaços.

\section{Crianças e famílias como público-alvo dos museus}

Na tentativa de oferecer serviços mais adequados para diferentes públicos, os museus começaram a se esforçar para apresentar exposições, atividades e programas atrativos para diversos grupos sociais e que atendessem aos seus interesses. Os grupos de famílias tornaram-se, especialmente nos Estados Unidos e na Europa, um importante público-alvo, devido ao papel educativo e à influência positiva que os familiares têm na formação dos hábitos culturais da criança. Por esta razão, alguns profissionais atuantes em museus sustentam que estas instituições devem refletir mais atentamente sobre o papel que podem ter nos processos educacionais e de socialização envolvendo famílias.

Estudos de público de famílias em museus têm sido foco de interesse contínuo nos últimos anos. Visam investigar como adultos e 
crianças, em grupos de família, se relacionam e interagem em exposições; o tempo gasto nos módulos expositivos; relações com o espaço; conversas entre os membros do grupo; comportamentos de adultos e crianças com relação ao material exposto; ganhos cognitivos e afetivos; aprendizado (learning-behaviours); comportamentos diferenciados conforme o sexo do indivíduo (gender effects); e planejamento e expectativas relacionados à visita ao museu (family agenda) (Bitgood et alii, 1994; Blud, 1990a, 1990b; Borun, 1995; Borun et alii, 1997; Brown, 1995; Butler, Sussman, 1989; Chaumier et alii, 1995; Dierking, Falcão, 1999; Falk et alii, 1998; Hilke, 1989; McManus, 1994).

Este artigo apresenta resultados da pesquisa de doutorado realizada na Grã-Bretanha (Studart, 2000), sobre três exposições interativas planejadas para o público infantil: All Hands Gallery, no National Maritime Museum, em Greenwich, distrito de Londres; Launch Pad, no Science Museum, localizado no centro de Londres; e Me \& My Body, no Eureka! The Museum for Children, na cidade de Halifax, norte da Inglaterra.

Estas exposições têm em comum o fato de terem sido planejadas e concebidas a partir de objetivos educacionais bem definidos:

- All Hands Gallery, do National Maritime Museum: visa estimular o desenvolvimento de habilidades de investigação e observação, bem como a cooperação e o trabalho em equipe; e promover uma experiência de aprendizado eficaz e agradável;

- Me \& My Body, do Eureka! The Museum for Children: tem o objetivo de aumentar o entendimento das crianças sobre o funcionamento do corpo humano, a fim de lhes propiciar uma melhor consciência do funcionamento do seu próprio corpo e das conseqüências de suas decisões sobre sua saúde;

- Launch Pad, do Science Museum: visa demonstrar aspectos da ciência e da tecnologia usados no dia-a-dia e introduzir princípios das ciências físicas relacionados a luz, som, forças, energia e estruturas.

Compreender as qualidades e dinâmicas da experiência de crianças e adultos, em exposições planejadas para o público infantil, assim como os elementos e características mais apreciados, pode ajudar educadores, curadores, designers e outros profissionais envolvidos na concepção de exposições a planejar espaços que melhor atendam às necessidades e expectativas desse público, de modo a oferecer uma experiência museal de maior qualidade.

\section{Motivações, metodologia e questões da pesquisa}

Uma das motivações para a realização da pesquisa foi investigar os benefícios das exposições planejadas para o público infantil em 
museus e a contribuição destas para a experiência museal do seu público-alvo: crianças e famílias.

O estudo buscou explorar percepções e comportamentos de crianças com idade entre sete e 11 anos e seus familiares nesse tipo de exposição, a fim de compreender os aspectos valorizados por esse segmento do público, assim como investigar de que maneira o design dessas exposições pode afetar o aprendizado e o comportamento de crianças e adultos nesses espaços. Também procurou verificar se as crianças e adultos se percebem em um espaço que estimula a aprendizagem, ou em um ambiente mais voltado para a diversão e o entretenimento. Buscou-se igualmente investigar a exposição como espaço de educação não-formal e de que forma o contexto social da visita 'em família' afeta a experiência museal das crianças. Grupos escolares não foram pesquisados, pois o objetivo era explorar as interações espontâneas entre os membros da família, em um espaço de educação não-formal.

A metodologia utilizada para investigar as percepções e os comportamentos de famílias em exposições planejadas para o público infantil inspirou-se em uma abordagem exploratória e naturalística de investigação, embora a pesquisa envolva métodos qualitativos e quantitativos. $\mathrm{O}$ estudo pode ser caracterizado como qualitativo porque envolveu pesquisa de campo - os dados foram coletados no seu ambiente natural, e as palavras e opiniões das pessoas investigadas foram a base dos dados registrados-, e descritivo porquanto observou a experiência e as idéias dos indivíduos investigados, além de seguir uma linha de investigação exploratória e indutiva, uma vez que buscaram-se 'padrões' durante a fase de análise, sem o propósito de testar hipóteses predeterminadas (Creswell, 1994). Sua natureza quantitativa evidencia-se na coleta e identificação dos dados com o objetivo de desenhar um quadro da situação investigada, a fim de examinar a freqüência com que os eventos ocorrem e explorar possíveis relações entre variáveis (Denzin, Lincoln, 1994, p. 4). Como afirmou Hedge (1995, p. 116) em sua palestra, na conferência Public Institutions for Personal Learning (Instituições públicas para a aprendizagem pessoal),

(...) a experiência museal deveria ser conceituada e analisada como uma experiência holística, como gestalt. A investigação desta experiência holística necessita um método de investigação multifacetado, capaz de acessar tanto dimensões afetivas como prazer e satisfação, quanto dimensões cognitivas como clareza da informação e subseqüente lembrança da experiência vivenciada.

Aspectos como comportamento do visitante, reações afetivas, opiniões e atitudes na exposição, elaboração pessoal da informação fornecida nos módulos, percepções sobre o ambiente e o contexto social da visita foram explorados na pesquisa. Não se pretendeu 
'quantificar' a aprendizagem nessas exposições, mas explorar se as crianças e os adultos entrevistados 'perceberam', segundo sua própria opinião, terem aprendido algo e/ou estarem em um espaço educativo, em um ambiente de aprendizagem.

As questões da pesquisa, originárias da literatura sobre museus como ambientes não-formais de aprendizagem e de estudos sobre crianças e famílias como visitantes em museus, foram as seguintes:

- Que aspectos da visita a uma exposição dirigida ao público infantil as crianças e seus acompanhantes adultos valorizam e por quê?

- Em uma exposição dirigida ao público infantil, as crianças e adultos se vêem em uma situação de aprendizagem, ou percebem a experiência mais como 'divertida'?

- Como as crianças vêem a visita a um museu em contexto familiar, comparada a uma visita em contexto escolar?

- Como os adultos e crianças se comportam em exposições dirigidas ao público infantil e quais são as dinâmicas familiares?

- Em que aspectos as exposições investigadas se assemelham-se e diferem e como suas diferenças afetam as experiências da criança e do adulto?

- Que variáveis (aspectos pessoal, social e físico do museu) podem influenciar as percepções de aprendizado de crianças e adultos, em uma exposição dirigida ao público infantil?

- A idade e o gênero podem afetar a experiência da criança e/ou do adulto, nesse tipo de exposição?

- Os objetivos educacionais das exposições investigadas foram alcançados?

- Que elementos dos aparatos interativos podem ser considerados bem-sucedidos, em exposições dirigidas ao público infantil?

O estudo enfatizou a importância de se adotar uma abordagem holística na investigação da experiência do visitante de museu, levando-se em consideração os contextos pessoal, social e físico da visita (Falk, Dierking, 1992) e o uso de uma metodologia indutiva de investigação.

Três diferentes métodos de investigação foram usados, para explorar as percepções e os comportamentos de crianças e adultos: entrevistas, observações discretas e desenhos infantis. Pesquisadores das ciências sociais concordam que o uso de métodos combinados (triangulação) pode oferecer resultados mais confiáveis, já que é possível cruzar os resultados obtidos por meio de diferentes instrumentos de pesquisa (Adler, Adler, 1994, p. 382; FrankfortNachmias, Nachmias, 1996, p. 204-5). Outro procedimento importante é testar os instrumentos de coleta de dados em campo e com o 
público-alvo da pesquisa, antes de iniciar a coleta de dados definitiva (Hein, 1998, p. 116).

Os métodos de investigação utilizados foram: entrevistas face a face, realizadas logo após a visita à exposição, com um adulto e uma criança na faixa etária de sete a 11 anos do grupo familiar (utilizaram-se dois questionários distintos para guiar as respectivas entrevistas, com perguntas abertas e fechadas); desenhos das crianças sobre o aparato preferido da exposição; e observações discretas das interações familiares em três aparatos interativos, em cada exposição investigada.

O número das amostras variou conforme o instrumento de investigação: foram entrevistadas 150 famílias (cinquenta em cada uma das três exposições), totalizando trezentos indivíduos (150 adultos e 150 crianças); coletaram-se 120 desenhos infantis; e 450 famílias foram observadas (150 famílias em cada exposição; cinquenta em cada aparato interativo observado).

O protocolo de perguntas que serviu de base para as entrevistas com os adultos buscou investigar os seguintes ítens:

\section{Número de visitas com a família ao museu}

(Freqüência anual de visitas a museus com a família; Razões pela qual o adulto trouxe a criança para visitar o museu; Tempo gasto na Exposição Interativa)

\section{Percepções sobre a exposição}

(Descrição da exposição; Descrição da 'atmosfera' da exposição; O que gostou e não gostou. Razões)

\section{Percepções sobre a experiência da criança}

(Percepção do envolvimento da criança com os módulos interativos. Satisfação em ver a criança realizando 'tal' atividade. Razões)

\section{Participação dos adultos com suas crianças}

(Uso dos módulos com as crianças)

Percepção dos adultos sobre o próprio aprendizado e a experiência museal

(Percepção sobre a experiência da visita. Percepção do 'próprio' aprendizado na exposição)

Opinião dos adultos sobre exposições para o público infantil em museus

Visitas a exposições para crianças em outros museus. Opiniões dos adultos sobre a oportunidade das crianças interagirem com módulos expositivos em museus)

\section{Identificação (dados completados pelo entrevistado)}

(Tipo de parentesco com a criança. Composição do grupo durante a visita. Faixa etária. Nível de escolaridade. Ocupação. Cidade onde mora) 
Nas entrevistas com as crianças, o protocolo de perguntas teve questões semelhantes às usadas no protocolo do adulto, visando uma comparação entre a visão do adulto e a da criança. Os itens investigados nas entrevistas das crianças estão descritos abaixo:

\section{Identificação}

(Nome da criança (sexo). Idade. Grupo de pessoas com o qual está visitando o museu)

\section{Desenho}

(desenho sobre algo que a criança gostou na galeria interativa)

\section{Percepções sobre as exposições interativas}

(Descrição da exposição - com as próprias palavras; Descrição da 'atmosfera' da exposição; O que gostou e não gostou. Razões)

\section{Percepções sobre a experiência museal}

(Módulo(s) preferido (s). Razões. Como se sentiu durante a visita à exposição. De que maneira prefere usar os módulos interativos: sozinha ou com alguém. Razões.)

\section{Percepções das crianças sobre o que aprenderam}

(A percepção de aprendizado pela criança durante a visita à exposição)

\section{Sobre exposições interativas}

(Porque a criança gosta de tocar/manipular os objetos. O que ela se lembra sobre a visita a outras exposições interativas.)

\section{Sobre o contexto social das visitas a museus}

(Pessoas com as quais a criança costuma visitar museus e número de visitas a museus realizadas anteriormente. Grupo com o qual a criança prefere visitar museus: com a família ou a escola. Razões.)

Os dados obtidos por meio das entrevistas foram analisados qualitativa e quantitativamente. $\mathrm{O}$ uso de testes estatísticos (chiquadrado) na análise das entrevistas com adultos e crianças é uma contribuição à análise de entrevistas com grupos familiares, devido ao método de tabulação cruzada das respostas dos adultos e das crianças. Os testes estatísticos indicaram associações significativas entre variáveis relacionadas a adultos, crianças, museus e visitação.

Para o levantamento dos comportamentos dos grupos familiares nas exposições interativas investigadas, recorreu-se a uma planilha de observação que contemplava dez variáveis comportamentais: composição do grupo; tempo gasto no módulo interativo; afastamento do grupo; manipulação direta do módulo; uso apropriado do aparato; tempo de espera para usar o módulo; atividades conjuntas de membros da família ou outras pessoas; proximidade com outros membros da família; leitura em voz alta para outras pessoas do grupo; tipo de conversa - 'dizer o que fazer', 'bate-papo' e 'explicação'. 
A análise dos desenhos feitos pelas crianças pode ser considerada um importante avanço nesse campo de investigação. As doze categorias extraídas dos desenhos (principais elementos dos aparatos; elementos de manipulação enfatizados no desenho; resultado/ efeito da manipulação; uso realístico de cores; representação da criança no desenho; indicação de textos/etiquetas; descrição de elementos do desenho; representação de experiência prazerosa; representação de um objeto do museu (não especificado); representação de diversos aparatos da exposição; aparato parcialmente representado; representação de interação social) visaram atribuir significado à interação das crianças com os aparatos interativos de sua preferência e proporcionaram achados qualitativamente diversos daqueles fornecidos pelas entrevistas e observações.

\section{Os achados}

Apesar dos resultados obtidos por meio desta pesquisa estarem associados ao contexto cultural do país em que a investigação foi desenvolvida (Grã-Bretanha), a metodologia adotada e os achados obtidos são uma contribuição para conhecimento sobre os públicos de museus (em especial o composto por famílias) e servem como referência e base de comparação para estudos na área realizados em outros países. No Brasil, ainda são poucas as pesquisas que tenham buscado 'conhecer' o público composto por grupos familiares que visitam os museus (Studart, 2002).

Os resultados da análise das observações, dos desenhos sobre as interações das crianças com os aparatos interativos e das respostas abertas e fechadas das entrevistas (analisadas qualitativa e estatisticamente, respectivamente) oferecem um panorama das percepções e experiências de crianças e famílias em exposições planejadas para o público infantil, e contribuem para a compreensão do cenário em que o público familiar visita esse tipo de exposição.

A seguir, os achados relativos às questões de investigação são apresentados com referência às análises dos resultados obtidos e à literatura sobre pesquisa de público em museus, seguindo-se uma discussão das implicações desses achados para o planejamento de exposições dirigidas ao público infantil e famílias.

\section{Que aspectos da visita a uma exposição dirigida ao público infantil as crianças e seus acompanhantes adultos valorizam e por quê?}

A análise das entrevistas indicou que pais e outros acompanhantes adultos manifestaram uma atitude entusiasmada com relação à oportunidade de as crianças interagirem com aparatos em museus, porque acreditam que isso motiva a criança para o aprendizado e a encoraja a visitar museus com maior freqüência. 
Pais e parentes consideraram as exposições dirigidas ao público infantil ambientes agradáveis, relaxados, amistosos, divertidos e educativos. As crianças perceberam as exposições como lugares estimulantes; viram-nas também como educativas e como espaços onde as pessoas podem aprender. Tiveram sentimentos positivos nesses espaços e relataram experiências prazerosas.

\section{Em uma exposição dirigida ao público infantil, as crianças e adultos se vêem em uma situação de aprendizagem, ou percebem a experiência mais como 'divertida'?}

Os comentários dos visitantes sugerem que a abordagem handson, usada nas exposições, é considerada, tanto pelos pais quanto pelas crianças, educativa e motivadora para o aprendizado infantil.

O termo 'divertido' não foi muito usado pelos pais e acompanhantes adultos para caracterizar a visita. As crianças adotaramno com maior freqüência do que os adultos, mas não foi este o comentário predominante, entre elas, para descrever as exposições (os relacionados a 'elogios' e 'sentimentos positivos' foram mais usuais). Quando indagadas a respeito de sua percepção de aprendizado nas exposições, cerca de 3/4 das crianças entrevistadas mencionaram ter aprendido algo.

As crianças e seus pais não consideraram as exposições apenas uma experiência divertida; manifestaram percepções ricas e variadas sobre as exposições e mencionaram explicitamente seu potencial educativo para a aprendizagem.

\section{Como as crianças vêem a visita a um museu em contexto familiar, comparada a uma visita em contexto escolar?}

Das crianças entrevistadas - todas britânicas, ou seja, provenientes da Inglaterra, Escócia, País de Gales ou Irlanda do Norte -, 61\% disseram preferir a visita a museus com a família em vez da escola. $\mathrm{O}$ estudo mostrou que, em suas visitas a museus com a família, as crianças valorizam a atenção pessoal e dedicada que recebem de seus pais e parentes, bem como a possibilidade de poder perguntar tão logo não compreendam algo, de ter mais independência para ir aonde quiserem e de poder passar mais tempo na exposição. As crianças britânicas desaprovaram sua falta de autonomia quando visitam o museu com o grupo escolar, os deveres solicitados e a falta de atenção individual por parte do professor. Tal resultado é semelhante ao obtido por Jensen (1994, p. 311), em pesquisa desenvolvida nos Estados Unidos acerca da visão das crianças sobre suas experiências em um museu, na qual a visita com família e amigos também obteve predileção entre a maioria dos entrevistados, que considerava o professor um empecilho a seu desejo de olhar e agir livremente.

No que se refere ao planejamento de exposições, depreende-se desses resultados que os museus devem proporcionar um ambien- 
te apropriado, tal como um espaço relaxado e amigável, para a interação familiar. Quanto às visitas escolares, o resultado indica que devem ser organizadas de modo mais flexível, considerando as características do ambiente educativo não-formal dos museus. Como enfatizou Salmi (1993, p. 183), em seu estudo sobre motivação e aprendizagem de crianças em visita escolar a um centro de ciências: "Os métodos escolares são transferidos muito facilmente para os cenários de educação não-formal ... mas os aspectos característicos do cenário não-formal precisam ser preservados, para que se mantenha e se desenvolva o seu valor como um meio de aprendizagem alternativo". As escolas não deveriam tentar 'transferir' seus métodos escolares para o ambiente educativo não-formal dos museus, mas sim reconhecer a natureza complementar das experiências de aprendizagem não-formal relativamente ao ensino formal.

\section{Como os adultos e crianças se comportam em exposições dirigidas ao público infantil e quais são as dinâmicas familiares?}

Os resultados das observações indicam que a 'manipulação dos aparatos interativos pelos adultos', nesse modelo de exposição, é influenciada pelo seu design e pelo tipo de museu que a abriga. Também sugerem que a manipulação em exposições hands-on varia de acordo com a natureza da tarefa e os aspectos físicos do aparato em questão.

De um modo geral, os adultos foram mais ativos na exposição All Hands Gallery (National Maritime Museum), menos ativos na Launch Pad (Science Museum) e ainda menos ativos em Me \& My Body (Eureka! The Museum for Children). A primeira exposição combinava aparatos interativos com objetos expostos em vitrines, tendo como objetivo atingir tanto o público infantil quanto o adulto. Continha um grande número de aparatos que exigia trabalho em equipe, de modo que os adultos tendiam a ajudar as crianças que estavam sob seus cuidados. Sobre os aparatos interativos observados na segunda exposição - apresentada como um espaço para 'todas as idades' -, os resultados mostraram que as crianças interagiam com eles bem mais do que os adultos. Estes deixavam que as crianças liderassem a atividade, assumindo, de um modo geral, o papel de acompanhante ou observador. A exposição Me \& My Body é um 'museu de crianças' (children's museum), cujo alvo específico é o público infantil. Neste espaço, os adultos pareciam se sentir inibidos de usar os aparatos interativos, por serem estes claramente dimensionados para crianças, o que os forçava a adotar o papel de observadores (até mesmo porque, devido às dimensões de alguns equipamentos, os adultos eram impossibilitados de usá-los).

Esses resultados parecem demonstrar que as abordagens interpretativas e a concepção da exposição (tema abordado, design, natureza da tarefa do aparato interativo, tempo de duração da 
1 Nos testes realizados, as probabilidades iguais ou inferiores a .05 foram consideradas estatisticamente significativas, como é usual nas ciências sociais. interação, uso individual ou em equipe etc.) afetam substancialmente a dinâmica familiar. Portanto, devem ser cuidadosamente considerados durante o desenvolvimento dos aparatos e avaliados antes de sua realização definitiva.

\section{Em que aspectos as exposições investigadas se assemelham e diferem e como suas diferenças afetam as experiências da criança e do adulto ${ }^{1}$}

O estudo mostrou que, apesar de terem em comum uma filosofia de aprendizagem baseada na experiência hands-on, as exposições diferem quanto a metas educativas específicas, assuntos, estilos de interpretação e características ambientais, e é provável que estes fatores afetem as percepções das crianças e de seus acompanhantes adultos, no que diz respeito a interações com o material exposto, aparatos e outras pessoas.

Os resultados estatísticos indicaram que a exposição Me \& My Body, do Eureka!, teve um impacto mais positivo na experiência afetiva e cognitiva das crianças do que as exposições All Hands e Launch Pad. A probabilidade de as crianças dizerem que 'aprenderam alguma coisa' $(p=.02)$ e que tiveram 'sentimentos positivos' $(p=.04)$ foi maior naquela exposição do que nas demais. Além disso, um dos resultados estatísticos indicou a tendência de as crianças preferirem usar os aparatos 'por conta própria' no Eureka! $(\mathrm{p}=.07)$, evidenciando uma maior autonomia da criança no uso da exposição ali montada.

É provável que o design e conteúdo do material exposto na galeria Me \& My Body (planejada especificamente para o público infantil e explorando o tema central 'como o corpo humano funciona') tivessem um forte impacto afetivo sobre a experiência das crianças, tornando-as mais confiantes no uso dos aparatos interativos e fornecendo maior suporte à percepção de aprendizado. As outras exposições foram planejadas para crianças, mas também para 'todas' as idades, e não se concentravam no desenvolvimento de um único tema. A exposição Me \& My Body, no Eureka!, oferecia mais informações sobre fatos que interessam diretamente o público infantil, ao passo que a estratégia de interpretação na exposição interativa Launch Pad, do Science Museum, deixava bastante espaço para que o próprio visitante interpretasse os fenômenos vivenciados. Além disso, as crianças eram familiarizadas com o assunto da exposição Me \& My Body (corpo humano), enquanto que, nas demais, os temas, das áreas de tecnologia e ciências, eram mais abstratos. Ou seja, as crianças podem se identificar mais facilmente com as informações sobre seu corpo do que com tópicos abstratos como tecnologia marítima ou fenômenos científicos.

No entanto, os resultados da análise dos desenhos das crianças indicam que os aparatos interativos da exposição Launch Pad eram 
os mais eficazes para provocar um impacto sobre a memória das crianças e as subseqüentes representações de características, cores e efeitos dos experimentos bem como as interações sociais ali vivenciadas. Embora estes achados aparentemente contradigam os resultados das entrevistas (que mostram uma percepção de aprendizado mais fraca, por parte das crianças, em Launch Pad do que nas outras duas galerias), na verdade podem indicar que a representação de um fenômeno - efeito da interação com os experimentos em Launch Pad - nem sempre foi considerada um 'aprendizado' pelas crianças. Como foi mencionado anteriormente, isso pode ser devido à estratégia de interpretação da exposição, que permitia aos próprios visitantes traduzirem os fenômenos vivenciados. Uma outra explicação possível é encontrada no modelo de assimilaçãoacomodação de Piaget: ao fazerem seus desenhos sobre a experiência com os aparatos interativos, as crianças ainda não haviam integrado os novos estímulos vivenciados em seus esquemas e, portanto, não perceberam os novos estímulos experimentados como 'aprendizado'.

A exposição Me \& My Body parece ter sido mais bem-sucedida em provocar sentimentos positivos nas crianças, provavelmente devido a seu design e ambiente dirigidos à infância. A All Hands Gallery obteve menos sucesso em causar um impacto sobre a memória e as emoções, em comparação com as outras duas galerias: nos desenhos das crianças, houve mais representações de uma 'visão geral' da visita ao museu do que nos demais. Pode ser que, por ter objetos expostos em vitrines, a percepção das crianças sobre a galeria como um espaço distinto em relação ao restante do museu (isto é, um espaço dedicado às crianças) tenha sido afetada.

Os resultados das observações sugerem que os assuntos abordados na All Hands Gallery apresentaram maior probabilidade de atrair homens e meninos, indicando um possível efeito de gênero (gender effect) nessa exposição. Em Launch Pad, os experimentos científicos atraíram as crianças em geral, tanto meninos como meninas. O menor envolvimento dos adultos nesta exposição pode dever-se à ausência de informações básicas sobre os experimentos, a que os adultos pudessem recorrer para 'ensinar' as crianças, ao contrário do que se via nas outras duas exposições. Ademais, no que se refere à programação visual, as letras pequenas e a impressão dos textos em 'preto e branco' não eram particularmente atraentes. Em Me \& My Body o ambiente colorido, incluindo a arquitetura, os aparatos interativos e os textos parecem ter atraído particularmente as crianças, uma vez que os resultados da análise sugerem que as crianças se sentiram confiantes e independentes para interagir com o material exposto.

Os achados descritos apontam, enfim, que um espaço projetado exclusivamente para crianças e que desenvolve um tema central, 
conceitualmente conexo e de interesse para elas, tem impacto mais positivo sobre o aprendizado, as emoções e a experiência infantil, mas pode conferir ao adulto um papel mais passivo. Porém tais resultados merecem ser aprofundados em futuras investigações.

\section{Que variáveis (aspectos pessoal, social e físico do museu) podem influenciar as percepções de aprendizado de crianças e adultos, em uma exposição dirigida ao público infantil?}

Os resultados estatísticos das entrevistas indicam quatro aspectos com probabilidade de encorajar a percepção da criança quanto ao seu aprendizado, em uma exposição dirigida ao público infantil: o tempo gasto na exposição ( $\mathrm{p}=.006)$; o tipo de museu (se é um 'museu das crianças', de ciências ou de caráter histórico) ( $\mathrm{p}=.02)$; a preferência das crianças pelo contexto social da visita (com a família ou com a escola) ( $\mathrm{p}=.04)$; e a relação de parentesco do adulto com a criança (mãe, pai ou outro parente) $(p=.05)$. Houve maior probabilidade de as crianças relatarem algum aprendizado ao passarem cerca de 'uma hora ou mais' na visita ao Eureka! - ambiente projetado especificamente para elas - e quando estavam com suas 'mães e parentes' (na amostra, as mães entrevistadas tinham um nível de escolaridade maior do que o dos pais). As crianças que não demonstraram preferência pelo contexto social da visita (familiar ou escolar) acusaram menor probabilidade de afirmar terem aprendido algo, o que pode indicar que aquelas com predileção pela família ou escola podem empenhar-se mais no processo de aprendizagem do que as que 'não têm preferência' alguma. Estes resultados mostram claramente que os aspectos pessoal, social e contextual afetam a percepção de aprendizado das crianças em exposições e que, para aumentar sua percepção de aprendizagem, elas precisam passar um tempo mínimo nas exposições (quanto maior o tempo de visita, maior a porcentagem de crianças a relatar ganho de aprendizagem).

Quanto aos adultos, sua percepção de aprendizagem, diferentemente do que ocorreu com as crianças, não pareceu ser afetada pelo tempo gasto na exposição $(\mathrm{p}=.28)$. Descobriu-se que o sexo do adulto (masculino ou feminino) tem muita probabilidade $(\mathrm{p}=.006)$ de afetar sua percepção de aprendizagem, em exposições planejadas para o público infantil. A probabilidade de mulheres relatarem que aprenderam algo foi maior que a de homens, sugerindo uma atitude diferente entre adultos dos dois gêneros face a suas experiências em exposições dessa natureza. Pode-se relacionar este achado com o que indicou maior probabilidade de as crianças relatarem algum aprendizado quando fizeram a visita com suas mães e parentes (conforme mencionado anteriormente, nessa amostra o nível de escolaridade das mães entrevistadas era maior do que o dos pais). Se as mães consideram a exposição como 'ambiente de aprendizagem', podem transmitir essa percepção e suas implicações a seus filhos e, 
assim, conferir uma 'estrutura de aprendizagem' à visita. Além disso, o nível de escolaridade do adulto pode afetar sua atitude diante das oportunidades educativas nesse tipo de exposição. Estes resultados nos permitem aludir ao estudo sobre aprendizagem familiar, realizado por Borun e outros (PISEC, 1998, p. 49), que indicou as mulheres com indicadores de desempenho significativamente mais altos do que homens, sugerindo serem aquelas "líderes/facilitadoras do aprendizado", pois facilitam a experiência de aprendizagem da família.

\section{A idade e o gênero podem afetar a experiência da criança e/ou do adulto, nesse tipo de exposição?}

Os resultados estatísticos das entrevistas mostram que atributos pessoais das crianças, tais como idade e sexo, têm probabilidade de afetar a experiência da criança e do adulto em exposições dirigidas ao público infantil. O tempo gasto na exposição $(p=.04)$, a preferência da criança nos modos de usar os aparatos interativos (sozinha ou com outra pessoa) $(\mathrm{p}=.02)$ e o fato de os adultos usarem ou não os aparatos com elas podem ser influenciados pela idade da criança.

Acusou-se maior probabilidade de as crianças mais novas (sete a nove anos) preferirem usar os aparatos "junto com alguém". Por conseguinte, houve menor probabilidade de os adultos utilizarem os aparatos com as crianças mais velhas (entre dez e 11 anos) do que com as mais novas. É possível que estas exijam mais atenção do que as da faixa etária maior, quando usam os aparatos interativos. Em seu estudo, Dierking $(1987$, p. 67) também concluiu que famílias com crianças mais novas apresentam um comportamento mais atencioso do que aquelas que acompanham crianças mais velhas.

Os resultados também apontam maior probabilidade de famílias com crianças de sete a nove anos passarem mais tempo nas exposições do que as acompanhantes de crianças entre dez e 11 anos, o que pode estar relacionado com o fato de crianças menores necessitarem de mais tempo para aprender a manipular os aparatos.

Quanto aos aspectos de gênero que afetam a experiência infantil, as meninas preferiram usar os aparatos 'junto com alguém', enquanto que os meninos 'não tiveram preferência' $(p=.04)$, sugerindo a probabilidade de serem estes mais independentes do que as meninas em exposições interativas, além da primazia, por parte destas, pelo uso dos aparatos em cooperação com outra pessoa. Semelhantemente, em seu estudo, Baker (1994) concluiu que meninas têm melhor desempenho em ambientes não-competitivos.

Entre as meninas houve também tendência a uma maior probabilidade de 'sentimentos negativos' ou 'neutros', ao interagir com os aparatos $(\mathrm{p}=.06)$. Além disso, a análise estatística indicou maior 
probabilidade de os meninos serem levados por suas famílias a outras exposições interativas, comparativamente às meninas $(p=.002)$.

Os resultados obtidos parecem estar indiretamente relacionados. Pode-se inferir que as exposições interativas são mais atraentes para meninos do que para meninas, porque estas demonstram menos entusiasmo do que aqueles, mas a hipótese merece ser investigada mais a fundo. É possível também que algumas exposições interativas, devido aos assuntos abordados ou à natureza das atividades, sejam mais atraentes para os meninos do que para as meninas (na All Hands Gallery, por exemplo, os meninos e os homens mostraram mais interesse em um jogo interativo denominado gunnery, sobre 'munições antigas de guerra', do que as meninas e as mulheres).

\section{Os objetivos educacionais das exposições investigadas foram alcançados?}

As análises indicam que a exposição Me \& My Body, no Eureka!, alcançou seus objetivos educativos - melhor compreensão, por parte das crianças, sobre o funcionamento do corpo humano e maior consciência de seus próprios corpos -, uma vez que a maioria do público infantil entrevistado (em torno de 80\%) manifestou ter aprendido algo na exposição e foi capaz de mencionar informações adquiridas e/ou aspectos da galeria que podiam relacionar consigo mesma.

A All Hands Gallery, do National Maritime Museum, também atingiu a maior parte de suas metas educativas, que incluíam não apenas ganhos de aprendizagem mas também a oferta de uma experiência prazerosa, o encorajamento de interações sociais e o estímulo de comportamentos de observação e investigação. A observação de grupos familiares revelou que essa exposição provocava mais atividades conjuntas entre os membros da família do que as demais, e os resultados das entrevistas indicaram que crianças e adultos ali passaram momentos agradáveis. A análise dos desenhos sugerem, entretanto, que as crianças tiveram mais dificuldade de representar os aparatos interativos desta exposição do que das outras duas, o que parece indicar que o design dos aparatos e as tarefas neles propostas eram, talvez, complexos demais para serem representados pelas crianças em sua totalidade.

Os objetivos educacionais da Launch Pad, no Science Museum, eram muito gerais (por exemplo, "demonstrar aspectos da ciência e tecnologia que as pessoas podem usar em seu dia-a-dia"), e isso refletiu-se nas percepções de aprendizado das crianças. Das entrevistas, 1/4 das crianças entrevistadas teve dificuldade para especificar o que havia aprendido. Um desses objetivos era levar os visitantes a estabelecer relações entre aspectos da ciência e tecnologia demonstrados nos aparatos e o cotidiano de suas vidas, mas a exposição 
fornecia poucas relações claras e exemplos concretos que ajudassem os visitantes a alcançar esse propósito. Por outro lado, a análise dos desenhos infantis sugere que esse tipo de exposição científica, com experimentos e seus efeitos imediatos e visíveis, influenciou fortemente a capacidade de as crianças recordarem as características do material exposto e seus efeitos. E talvez essas lembranças possam, posteriormente, ajudar o estabelecimento de relações.

\section{Que elementos dos aparatos interativos podem ser considerados bem-sucedidos, em exposições dirigidas ao público infantil?}

Com base nas observações, selecionaram-se nove atributos considerados atraentes em aparatos interativos de exposições dirigidas ao público infantil: oportunidade de experimentar algo novo; oportunidade de representar um papel (ser outra pessoa, estar em outro tempo/lugar); elemento de surpresa (assistir algo acontecer); elemento de diversão; situação desafiadora; jogo/máquina interativo(a); design de dimensões apropriadas para a criança; oportunidade para uso do aparato em equipe; e design 'imaginativo'. Foram estes os atributos observados nos aparatos que as crianças elegeram como seus favoritos, portanto merecem ser considerados na elaboração de exposições para o público infantil, a despeito do desafio que representa, para os planejadores, a incorporação de todos eles. O estudo indica, por exemplo, que atributos como 'oportunidade para uso do aparato em equipe' não se encontravam com freqüência nas exposições investigadas e poderiam ter sido incorporados mais vezes, especialmente se o intuito for encorajar a participação de meninas.

\section{Implicações dos resultados da pesquisa}

\section{Modelo sugerido para o desenvolvimento de uma exposição dirigida ao público infantil}

Com base na revisão da literatura (Miles et alii, 1988; Bagchi, Cole, 1992; Sykes, 1994; Thomas, 1994; Borun, Dritsas, 1997; Guichard, 1998; Hein, op. cit.; Caulton, 1998) e nos resultados obtidos, sugere-se um modelo educativo para o desenvolvimento de uma exposição dirigida ao público infantil. Ele oferece um conjunto de idéias básicas e pode ser adaptado a diferentes situações nos museus, tais como projetos desenvolvidos por equipe interna ou empresas contratadas.

O modelo indica a importância de equipe multidisciplinar em processo participativo e o uso de avaliação, para assegurar uma interpretação e um design ergonômico dos aparatos adequados às necessidades das crianças. A equipe da exposição pode ser composta por profissionais internos e externos - museólogos, educadores, comunicadores, projetistas, psicólogos, historiadores, consultores, 
avaliadores, arquitetos etc. Nos estágios iniciais do processo, os objetivos educacionais e de aprendizagem precisam ser claramente definidos para orientar o projeto da exposição.

Teorias de cognição e aprendizagem desenvolvidas por Piaget (Wadsworth, 1996), Vygotsky (1978) e Gardner (1993), entre outras, podem oferecer idéias para as abordagens educativas a serem adotadas no planejamento da exposição, tais como encorajar a solução de problemas apresentando um desafio a realizar (Bagchi, Cole, op. cit., p. 99), dar oportunidades para o uso social do material exposto e oferecer diferentes modalidades/entradas de aprendizagem em um módulo expositivo. O processo participativo é uma exigência-chave das exposições dirigidas às crianças, tanto no planejamento como na elaboração da abordagem comunicativa/ interpretativa. Nele a contribuição infantil é essencial, por meio de avaliação preliminar (front-end) e formativa. A avaliação front-end examina se o conteúdo da exposição está de acordo com o interesse e a faixa etária das crianças (Thomas, op. cit.). A avaliação formativa testa, por meio de protótipos, o uso pelas crianças dos objetos da exposição, além de resolver eventuais problemas ergonômicos. A reflexão sobre essas questões pela equipe da exposição é importante para o sucesso do desenvolvimento de exposições dirigidas ao público infantil.

\section{Implicações para o planejamento de exposições dirigidas ao público infantil e familiar}

Os resultados indicam que um espaço projetado exclusivamente para o público infantil (embora de acesso permitido também a adultos) e com módulos conceitualmente conexos pode aumentar a percepção de aprendizagem das crianças. No entanto, é importante estar atento para o fato de que os resultados das entrevistas demonstraram que o design de alguns módulos interativos provocou 'sentimentos negativos' em $17 \%$ das crianças $(n=25$, de 150). Ao interagir com certos aparatos, algumas crianças expressaram sentimentos negativos associados à "auto-imagem" (tais como sentirse 'nervoso' ou 'envergonhado') e a "incômodo físico" (problemas de projeto - por exemplo, o aparato 'é duro' ou 'machuca'). É importante que planejadores e projetistas ponderem tais informações a fim de evitar que aparatos interativos causem sentimentos de malestar físico ou emocional, e dediquem atenção especial aos aspectos ergonômicos de módulos interativos a ser utilizado por crianças.

A análise dos desenhos das crianças ratifica (por 1/4 da amostra) a relevância da linguagem e do texto nas exposições a elas dirigidas. A palavra escrita deve ser objeto de cuidadosa consideração pelos planejadores, ao elaborarem exposições para públicos de sete a 11 anos de idade. Para esta faixa etária, os resultados nos levam a recomendar enfaticamente a adoção de painéis e etiquetas que expli- 
quem a finalidade da manipulação (em lugar de textos que apenas instruam sobre seu uso) e forneçam exemplos que ajudem os visitantes a estabelecer relações com suas próprias experiências e encorajem discussões adicionais com outros membros do grupo e conversações dos tipos 'bate-papo' e 'explicação' entre crianças e adultos.

\section{Como as exposições dirigidas ao público infantil podem dar suporte ao aprendizado familiar e favorecer a experiência social da família, em museus?}

As exposições para o público infantil podem constituir importante experiência de sociabilidade entre os membros da família, ao lhes oferecer uma oportunidade de convívio de boa qualidade, tão valioso no contexto familiar contemporâneo. Esses espaços permitem aos pais observar e acompanhar o desenvolvimento de seus filhos e compartilhar com eles as suas experiências, ao mesmo tempo que oferecem às crianças a chance de se divertirem e aprenderem com seus parentes.

Entre os três tipos de conversa observadas nas exposições investigadas, houve uma grande proporção dos tipos 'dizer o que fazer' e 'bate-papo' entre adultos e crianças, em oposição à 'explicação'. Conversas do primeiro tipo dão à criança menos autonomia para explorar o aparato por conta própria, o que pode inibir seu aprendizado e sua capacidade de resolver problemas. Por esse motivo, devem ser encorajadas, nas exposições para crianças, conversas do tipo 'bate-papo' e 'explicação', estimuladas por meio do conteúdo e da linguagem dos textos, que devem ser informais, simples e claros e incorporar perguntas aos visitantes e sugestões de atividades.

Pesquisas com grupos de família realizadas em outros museus (PTM, 1998, p. 54) também mostraram que as instruções indiretas de adultos para crianças (tais como dicas e perguntas reflexivas) podem criar mais oportunidades de aprendizagem do que as instruções diretas (tais como orientações informando e/ou demonstrando às crianças como resolver problemas). Portanto, as exposições dirigidas ao público infantil devem buscar informar os pais e acompanhantes adultos sobre a influência dos diferentes tipos de apoio à criança no aprendizado e empenho destas (idem, ibidem, p. 55). Estudos anteriores (Dierking, op. cit., p. 78) enfatizaram também o papel do museu no preparo dos pais para a maximização das experiências de aprendizagem não-formal de seus filhos em exposições.

\section{Estratégia de desenvolvimento do público de famílias em museus}

Os dados demográficos da amostra investigada revelam que, ao contrário do que apontam algumas pesquisas (de que o público de museus é, em geral, altamente instruído), as exposições dirigidas 
ao público infantil têm um potencial 'popular' e atraem visitantes de todos os níveis de escolaridade. Nas três exposições pesquisadas, metade de todos os acompanhantes adultos entrevistados havia deixado o colégio com 18 anos de idade ou menos, isto é, possuía o segundo grau completo ou incompleto. Este resultado sugere que, na Grã-Bretanha, adultos com diferentes níveis de instrução estão interessados em proporcionar a seus filhos oportunidades educativas e que os museus podem contribuir por meio de exposições organizadas para o público infantil e familiar. Além disso, as estatísticas obtidas indicam que as famílias britânicas entrevistadas são visitantes freqüentes de museus e desse tipo de exposição.

\section{Sugestões para ulteriores investigações sobre o tema}

A pesquisa permitiu apontar questões a serem aprofundadas, tais como: as exposições dirigidas ao público infantil devem ser projetadas exclusivamente para crianças, ou devem se propor também a despertar o interesse de seus acompanhantes adultos? Os módulos da exposição devem estar conceitualmente conectados e desenvolver um tema central, a fim de estimular o aprendizado, ou podem ser conceitualmente independentes? Como introduzir assuntos desconhecidos para as crianças, em exposições dessa natureza?

Investigações a respeito de como o gênero afeta a experiência da criança e do adulto, nesse tipo de exposição, merecem igualmente ser realizadas, uma vez que os presentes resultados denotam um interesse maior dos meninos do que das meninas. Será o entusiasmo destas pelas exposições hands-on igual ao dos meninos? Que assuntos são preferidos pelas meninas e pelos meninos, e por quê?

Outro aspecto entusiasmante para futuros estudos refere-se à aplicação de teorias de aprendizagem no design de exposições dirigidas ao público infantil.

Finalmente, como a pesquisa aqui apresentada foi uma das primeiras a utilizar desenhos para investigar as interações das crianças com aparatos interativos em uma exposição dirigida ao público infantil, outros estudos com o mesmo recurso seriam úteis para o aperfeiçoamento dessa metodologia.

\section{Considerações finais}

Uma motivação importante para a presente investigação foi estimar o valor e o potencial das exposições dirigidas ao público infantil como recurso específico para crianças e famílias nos museus. O estudo ofereceu várias contribuições para os estudos sobre visitantes e o campo da educação não formal em museus, no que se refere ao público infantil e familiar, e proporcionou abordagens 
metodológicas originais de análise como, por exemplo, a análise de desenhos feitos pelas crianças.

A pesquisa examinou essas exposições exclusivamente do ponto de vista de seu público-alvo (crianças e famílias). O uso de diferentes instrumentos de investigação (entrevistas, observações e desenhos) sobre percepções e comportamentos de crianças e adultos permitiu a triangulação dos resultados, conferindo, assim, maior consistência aos achados.

Esta investigação abriu caminho para o estudo de exposições dirigidas ao público infantil como um ambiente de exposição característico e com aspectos específicos. A originalidade do estudo está no que revela sobre as experiências familiares em exposições dirigidas à criança e em sua abrangência, incluindo o ambiente, a abordagem interpretativa e o design dos módulos expositivos e aparatos interativos. Inova os estudos da área ao comparar as experiências e percepções de crianças e adultos em três diferentes museus (um museu marítimo - National Maritime Museum -, um de ciências - Science Museum - e um 'museu das crianças' - Eureka! The Children's Museum), com exposições de características distintas (All Hands Gallery, Launch Pad, e Me \& My Body, respectivamente).

Seus resultados fornecem um importante conjunto de dados empíricos sobre o comportamento natural das famílias em exposições dirigidas ao público infantil e, também, sobre as visões e percepções dos próprios adultos e crianças quanto as suas experiências de aprendizagem nesses espaços, dados estes que podem ser usados como referência por profissionais envolvidos no planejamento de exposições dirigidas ao público infantil ou atividades educativas para crianças e famílias em museus.

Por terem sido investigadas três diferentes exposições dirigidas ao público infantil, os resultados oferecem uma ampla visão das experiências das crianças, de seus pais e parentes, dos aspectos que podem afetar suas percepções e seus comportamentos e de como as diferenças entre esses espaços afetam as experiências da criança e da família durante a visita.

$\mathrm{O}$ estudo demonstrou que exposições dessa natureza influem positivamente no convívio da família, pois estas experiências podem ser consideradas como catalisadores da interação familiar. Além disso, as crianças perceberam ganhos de aprendizagem nesse ambiente.

Se integrados à política de comunicação do museu e projetados com criatividade - utilizando uma abordagem dirigida à criança, porém atenta a aspectos que afetam o comportamento e o aprendizado familiar -, tais ambientes podem oferecer um espaço singular e constituir-se em um importante produto cultural e educativo para o público infantil e famílias. 


\section{REFERÊNCIAS BIBLIOGRÁFICAS}

Adler, P., Adler, P. 1994

Anderson, D. 1997

Bagchi, S. K.; Cole, P. R. 1992

Baker, D.

1994

Bitgood, S. et alii 1994

Blud, L.

1990a

Blud, L.

$1990 b$

Borun, M.

1995

Borun, M., Dritsas, J. 1997

Borun M. et alii 1997

Brown, C. 1995

Butler, B. H.; Sussman, M. B. (eds.) 1989

Caulton, $\mathrm{T}$. 1998

Chaumier, S. et alii 1995

Creswell, J. 1994

Denzin, N., Lincoln, Y. (eds.) 1994

Dierking, L. 1987

Falcão, D.
Observation techniques. In: N. Denzin, Y. Lincoln (eds.).

Handbook of qualitative research. New York, Sage Publications, p. 377-92.

A common wealth: museums and learning in the United Kingdom.

London, Department of National Heritage.

The piagentian children's science gallery.

Curator, 35(2), p. 95-104.

I am what you tell me to be: girls in science and mathematics.

In: Association of Science-Technology Centers. What research says about learning in science museums, v. 1. Washington DC, ASTC, p. 30-4.

The impact of informal education on visitors to museums. In: V. Crane et alii (eds.). Informal science learning. Dedham, MA, Research Communications, p. 61-106.

Social interaction and learning in family groups visiting a museum. International Journal of Museum Management and Curatorship, v. 9, n. 1, p. 43-51.

Sons and daughters: observations on the way families interact during a museum visit. International Journal of Museum Management and Curatorship, v. 9, n. 2, p. 257-64.

Family learning in museums: a bibliographic review.

Curator, v. 38 , n. 4, p. 262-70.

Developing family friendly exhibits.

Curator, v. 40, n. 3, p. 178-96.

Enhancing family learning through exhibits.

Curator, v. 40, n. 4, p. 279-95.

Making the most of family visits: some observations of parents with children in a museum science centre. Museum Management and Curatorship, v. 14 , n. 1, p. 65-71.

Museum visits and activities for family life enrichment.

Nova York, Haworth Press.

Hands-on exhibitions: managing interactive museums and science centres. Londres, Routledge.

Les accompagnateurs de la Cité des Enfants: étude des public individuels.

Paris, La Cité des Sciences et de l'Industrie/Départment Evaluation et Prospective.

Research design.

Londres, SAGE Publications.

Handbook of qualitative research.

Londres, SAGE Publications.

Parent-child interactions in a free choice learning setting: an examination of attention-directing behaviors. Unpublished Ph.D. thesis. Flórida, University of Florida.

Padrões de Interação e Aprendizagem em Museus de Ciências. Dissertação de Mestrado em Educação, Gestão e Difusão em Biociências. Departamento de Bioquímica Médica do Instituto de Ciências Biomédicas, Universidade do Estado do Rio de Janeiro. 
Falk, J., Dierking,

L. (eds.)

1995

Falk, J., Dierking, L. 1992

Falk, J. et alii 1998

Frankfort-Nachmias, C., Nachmias, D. 1996

Gardner, H. 1993

Guichard, J. 1998

Hedge, A. 1995

Hein, G. E. 1998

Hilke, D. D. 1989

Jensen, $\mathrm{N}$. 1994

McManus, $\mathrm{P}$. 1994

Miles, R. S. 1998

Miles, R. S et alii 1988

PISEC. 1998

Please Touch Museum (PTM) 1998

Salmi, H. 1993

Studart, D. C. 2003

Studart, D. C. et alii 2003
Public institutions for personal learning: establishing a research agenda. Washington DC, American Association of Museums.

The museum experience.

Washington DC, Whalesback Books.

The effect of visitor's agendas on museum learning.

Curator, v. 41, n. 2, p. 106-20.

Research methods in the social sciences.

Londres, Arnold.

Multiple intelligences: the theory in practice.

Nova York, Basic Books.

Adapter la museologie aux enfants. In: B. Schiele, E. Koster (eds.). La revolution de la museologie des sciences. Lyon, Presses Universitaires de Lyon, p. 207-47.

Human-factor considerations in the design of museums to optimize their impact on learning. In: J. Falk, L. Dierking (eds.). Public institutions for personal learning: establishing a research agenda. Washington DC, American Association of Museums, p. 105-18.

Learning in the museum.

Londres, Routledge.

The family as a learning system: an observational study of families in museums. In: Butler, Sussman (eds.). Museum visits and activities for family life enrichment. Nova York, The Haworth Press.

Children's perceptions of their museum experiences: a contextual perspective. Children's Environment, v. 1, n. 4, p. 300-24.

Families in museums. In: R. Miles, L. Zavala (eds.). Towards the museum of the future: new european perspectives. Londres, Routledge, p. 81-97.

Connaitre ce que font les visiteurs au musée. In: B. Schiele, E. Koster (eds.). La revolution de la museologie des sciences. Lyon, Presses Universitaires de Lyon, p. 249-66.

The design of educational exhibits.

Londres, Unwin Hyman.

Family learning in museums: the PISEC perspective. Filadélfia, Philadelphia/ Camden Informal Science Education Collaborative (PISEC), Franklin Institute.

Project Explore: A two-year study on how and what young children learn in children's museum. Filadélfia, Please Touch Museum.

Science centre education: motivation and learning in informal education. Research Report, n. 119. Helsinque, Department of Teacher Education/University of Helsinki.

Famílias, exposições interativas, e ambientes motivadores em museus: $\mathrm{O}$ que dizem as pesquisas?. Avaliação e estudos de públicos no Museu da Vida. Caderno do Museu da Vida. Rio de Janeiro, Museu da Vida. p. 33-42.

Pesquisa de público em museus: desenvolvimento e perspectivas. Em Gouvêa, G. et alii (org.). Educação e museu: a construção social do caráter educativo dos museus de ciência. Rio de Janeiro, Access Editora. p. 129-57. 
Studart, D. C.

set. 2002

Studart, D. C. 2000

Studart, D. C. 1997

Studart, D. C. 1996

Sykes, M. 1994

Thomas, G. 1994

Vygotsky, L. S. 1978

Wadsworth, B. 1996
O aprendizado não-formal no contexto familiar de uma visita a um museu de ciências. Relátorio final. Bolsa de Fixação de Pesquisador da Fundação de Amparo à Pesquisa do Estado do Rio de Janeiro (Faperj). Pesquisa desenvolvida no Museu de Astronomia e Ciências Afins (MAST), Rio de Janeiro.

The perceptions and behaviour of children and their families in child-orientated museum exhibitions. Tese de doutoramento, Londres, Department of Museum and Heritage Studies/University College London (Cópia no Museu de Astronomia e Ciências Afins/MAST), Rio de Janeiro.

Educational or just fun? The perceptions of children and their families in a child-orientated museum exhibition. Journal of Education in Museums, v. 18, p. 26-8.

The use of computer-based exhibits in a children's gallery: a case study. In: H. Krautler (ed.). New strategies for communication in museums. Proceedings of ICOM/CECA Conference, Austria. Paris, International Council of Museums/Committee for Education and Cultural Action, p. 94-97.

Research review on museum-based learning in early childhood. Paper integrante do seminário Learning in Museums, organizado pela American Association of Museums, held in Chicago, EUA, 1995.

Why are you playing at washing up again? Some reasons and methods for developing exhibitions for children. In: R. Miles, L. Zavala. Towards the museum of the future. Londres, Routledge.

Mind in society: the development of higher psychological processes. Cambridge: Harvard University Press. Editado por M. Cole, V. John-Steiner, S. Scribner and E. Souberman.

Piaget's theory of cognitive and affective development.

Nova York, Longman. $5^{\underline{\underline{a}}}$ ed.

Recebido para publicação em fevereiro de 2003.

Aprovado para publicação em junho de 2004. 